\title{
AVALIAÇÃO DA INFLUÊNCIA DE SUBSTÂNCIAS FENÓLICAS E CAROTENOIDES NA ANOMALIA DO EPICARPO DA GOIABA, “ANELAMENTO"1
}

\author{
TAIJI WATANABE ${ }^{2}$, DANILO EDUARDO ROZANE 3 , \\ WILLIAM NATALE ${ }^{4}$, CLAUDIA MARIA FURLAN ${ }^{5}$
}

\begin{abstract}
RESUMO - A anomalia do epicarpo da goiaba, comumente relatada por agricultores e técnicos como o "anelamento juvenil da goiaba", tem causado preocupação devido à desinformação sobre o assunto. O objetivo deste estudo foi analisar quimicamente as concentrações de substâncias fenólicas e carotenoides na região do epicarpo de goiabas afetadas pelo "anelamento", visando a caracterizar essa anomalia previamente relatada. Foram analisadas substâncias fenólicas (taninos, flavonas/flavonóis, antocianinas e fenóis totais) e carotenoides em epicarpos de frutos verdes e maduros de goiabeiras cv. Paluma, com e sem anomalia. O delineamento experimental adotado foi o inteiramente casualizado, sendo estabelecidos seis tratamentos com o epicarpo dos frutos maduro sem anomalia na região inferior (FMSI); frutos maduros sem injuria na região superior (FMSS); frutos verdes sem anomalia na região inferior (FVSI); frutos verdes sem anomalia na região superior (FVSS); frutos verdes com anomalia na região inferior (FVCI); frutos verdes com anomalia na região superior (FVCS). Dentre as substâncias analisadas, os carotenoides, os taninos e os fenóis totais mostram indicativos para a caracterização do anelamento. Tanto substâncias fenólicas quanto carotenoides apresentam propriedades antioxidantes e, dessa forma, poderiam estar relacionadas à defesa antioxidante causada por um fator de estresse ainda desconhecido, que promove o "anelamento" característico apresentado pelas goiabas..
\end{abstract}

Termos para indexação: Psidium guajava, anomalia, tanino, fenóis, carotenoides, fruta.

\section{PHENOLIC COMPOUNDS AND CAROTENOIDS AMOUNTS ON GUAVA EPICARP INJURY, 'GIRDLING'}

\begin{abstract}
Guava epicarp injuries, popularly known as "girdling", have been concerned technicians and producers due to misunderstand about their causes. The objective of this study was to analyze the amounts of phenolic compounds and carotenoids present on guava epicarp region affected by injury ("girdling") in order to characterize chemically those regions. Concentrations of phenolic compounds (tannins, flavones/ flavonols, anthocyanins and total phenolic compounds) and carotenoids were analyzed on tissue from unripe and ripe guava injured and non-injured epicarp fruits (Psidium guajava cv. Paluma). The experimental design was randomized, and were established six treatments: epicarp from ripe fruit without injury in the lower (FMSI) and upper region (FMSS) of the fruit, unriped fruit without injury (lower - FVSI - and upper region - FVSS), injured unriped fruit with injury (lower - FVCI - and upper region - FVCS). Higher concentrations of phenolic compounds, carotenoids of tannins, were found on tissues of unripe fruit epicarp with "girdling" when compared with health epicarps. Results showed the participation of phenolics compounds (tannins) and carotenoids as possible substances that characterized the injury formation. Although phenolic compounds and carotenoids have antioxidant properties and are often related as antioxidant defenses, the causes of "girdling" of guava fruits are still unknown.
\end{abstract}

Index terms: Psidium guajava, tannins, phenols, carotenoids, fruit, injuries.

\footnotetext{
'(Trabalho 065-10). Recebido em: 05-03-2010. Aceito para publicação em: 24-05-2010.

${ }^{2}$ Graduando do Dept ${ }^{\circ}$. de Botânica, Instituto de Biociências da Universidade de São Paulo-USP. Rua do Matão, 277, Cidade Universitária, CEP: 05508-090 - São Paulo. Bolsista CNPQ. E-mail:taijiwatanabe@gmail.com

${ }^{3}$ Pós-Doutorando, Dept $^{\circ}$. Solos e Adubos, Universidade Estadual Paulista, Faculdade de Ciências Agrárias e Veterinárias (FCAV/ Unesp). Via de Acesso Prof. Paulo Donato Castellane, s/n. 14870-000 Jaboticabal-SP. E-mail: danilorozane@yahoo.com.br ${ }^{4}$ Professor Adjunto, Dept ${ }^{\circ}$. de Solos e Adubos, FCAV/Unesp. Bolsista PQ do CNPq. E-mail: natale@fcav.unesp.br ${ }^{5}$ Professora Doutora, Dept ${ }^{\circ}$. de Botânica, Instituto de Biociências da Universidade de São Paulo-USP. Rua do Matão, 277 Cidade Universitária - São Paulo-SP, Cep 05508-090. Email: furlancm@ib.usp.br
} 


\section{INTRODUÇÃO}

A goiaba é apreciada não apenas pelo seu sabor e aroma característicos, mas também pelo valor nutritivo, além de suas potencialidades fitoquímicas no desenvolvimento de fitocosméticos (IHA et al., 2008).

O mercado de frutas para o consumo in natura e para suprir a indústria com matéria-prima apresenta-se promissor para inúmeras frutíferas, como as goiabeiras, que encontram condições edafoclimáticas adequadas para ser cultivada em todo o território nacional. Além disso, ela tem potencial para produzir durante o ano todo, se o manejo agronômico do pomar considerar as exigências da cultura, desde o plantio de mudas propagadas por estaquia, ou seja, vegetativamente (ROZANE et al., 2009). Assim, após a poda de formação, tem início a frutificação, pois as gemas estimuladas já possuem idade fisiológica para o florescimento.

Contudo, no início de produção, as plantas de goiabeira propagadas vegetativamente apresentam, por vezes, frutos com anomalias, que ocorrem somente no epicarpo sendo comumente relatada pelos agricultores e técnicos como o "anelamento juvenil da goiaba". Salienta-se que a ocorrência de frutos com esses sintomas é aleatória na planta, estando presente isoladamente em um ramo, ou apresentando ramos com todos os frutos comprometidos (Figura 1). A ocorrência e a severidade de frutos com sintomas são variáveis em cada talhão, desaparecendo quando as plantas atingem idade adulta, cerca de 4 a 5 anos.

Devido ao aspecto visual do epicarpo, os frutos tornam-se inviáveis para o consumo in natura, contudo podem ser aproveitados para a industrialização, pois a anomalia "anelamento" somente afeta o epicarpo dos frutos, não comprometendo a polpa.

O que tem causado preocupação é a desinformação sobre o assunto, por não haver indicações na literatura sobre a causa desta anomalia nas goiabas, acarretando tentativas de controle de forma empírica e sem sucesso, por parte de produtores e técnicos.

Alguns trabalhos relatam a ocorrência de anomalias foliares, visíveis em folhas de goiabeira, quando em presença de ozônio (SINGH et al., 1994), ou ataques severos de fungos (COLEY; AIDE, 1989). Entretanto, informações sobre distúrbios fisiológicos que podem levar a anomalia na casca (epicarpo) de goiabas são inexistentes.

O objetivo deste estudo foi caracterizar a região do epicarpo de goiabas afetadas pelo "anelamento", em relação às concentrações de substâncias fenólicas (antocianinas, taninos e flavonoides) e carotenoides.

\section{MATERIAL E MÉTODOS}

Foram analisados epicarpos de frutos verdes e maduros de goiabeiras (Psidium guajava L.), cultivar Paluma, com e sem "anelamento". Os frutos foram coletados em um talhão comercial no município de Cabrália Paulista-SP, com coordenadas geográficas de $22^{\circ} 27^{\prime} \mathrm{S}$ de latitude e $49^{\circ} 20^{\prime} \mathrm{W}$ de longitude, e altitude de 539 metros.

Frutos maduros e verdes foram divididos em duas partes: região inferior e superior (afetadas ou não pelo "anelamento") (Figura 1a), para a raspagem do epicarpo, devido à anomalia restringir-se a estas regiões e não comprometer o mesocarpo e o endocarpo. O delineamento experimental adotado foi o inteiramente casualizado, estabelecendo-se seis tratamentos com o epicarpo dos frutos maduro sem anomalia na região inferior (FMSI); frutos maduros sem injúria na região superior (FMSS); frutos verdes sem anomalia na região inferior (FVSI); frutos verdes sem anomalia na região superior (FVSS); frutos verdes com anomalia na região inferior (FVCI); frutos verdes com anomalia na região superior (FVCS).

Para a coleta do epicarpo, foram feitas raspagens em 48 frutos para cada um dos seis tratamentos. Cada tratamento teve seis repetições e cada repetição foi resultado da combinação da raspagem de oito frutos. Em seguida, o epicarpo foi congelado em nitrogênio líquido, colocado em vidro âmbar e conservado em freezer a $-80^{\circ} \mathrm{C}$.

As análises de substâncias fenólicas totais e taninos totais seguiram os protocolos adaptados de Waterman e Mole (1994).Flavonas/flavonóis foram quantificados segundo Motta (2002), enquanto os teores de antocianinas foram analisados de acordo com a American Herbal Pharmacopédia (2010). Carotenoides foram quantificados de acordo com o protocolo adaptado e as equações de Wellburn (1994). Cada análise foi feita em triplicata. Os protocolos foram adaptados, diminuindo-se proporcionalmente os reagentes, amostras e solventes utilizados.

Para o cálculo das concentrações de fenólicos totais, taninos totais e flavonas/flavonóis, foram utilizadas curvas de calibração com ácido gálico, ácido tânico e quercetina, respectivamente.

Realizou-se análise de variância, pelo teste $\mathrm{F}$, e as médias dos tratamentos foram comparadas entre si, pelo teste de Tukey $(\mathrm{p}<0,01)$, com o auxílio do programa ESTAT (1992). 


\section{RESULTADOS E DISCUSSÃO}

A análise estatística de variância indicou haver diferença significativa ao nível de $\mathrm{p}<0,01$ de probabilidade. Ao comparar as médias dos tratamentos, a maior porcentagem significativa de substâncias fenólicas foi encontrada em FVCI, apontando para a participação dessas substâncias na caracterização da anomalia apresentada pelo fruto. Bolwell et al. (1985) relatam que o aumento de substâncias fenólicas está relacionado com respostas de defesa da planta a injúrias causadas por patógenos, por exemplo. Em estudos para prevenção de injúrias, causadas por condições de estocagem em baixas temperaturas, foi demonstrado que o aumento de substâncias fenólicas no fruto de goiaba diminui o grau de injúria (AGUILAR et al., 2004).

Dentre as substâncias fenólicas testadas neste estudo (taninos e flavonoides), as porcentagens de taninos totais nos tratamentos FMSI e FMSS foram significativamente menores, seguidas pelas presentes nos tratamentos FVSI e FVSS, estando as maiores concentrações no fruto verde com "anelamento", sendo o maior valor determinado no tratamento FVCI (Tabela 1). Dessa forma, o acúmulo de taninos totais pode estar relacionado com o desenvolvimento da região injuriada, como também relatado em folhas de $P$. guajava tratadas com ozônio, nas quais a injúria apresentava maiores concentrações de taninos (REZENDE; FURLAN, 2009).

Maldonado et al. (2002), estudando frutos de Cherimoia, observaram que as regiões danificadas por condições de estocagem em baixas temperaturas apresentaram mudança em sua textura, tornando-se mais rígidas, acompanhadas por aumento na concentração de taninos. É provável que as duas características estejam ligadas, já que taninos associados à parede celular conferem rigidez a essa estrutura (CHALKER-SCOTT; KRAHMER, 1989). Isso poderia explicar a mudança de textura na região do "anelamento" das goiabas, apresentando-se como uma mancha amarronzada, provocada pelo aumento da rugosidade da casca.

As diferenças qualitativas e, especialmente, quantitativas de carotenoides ocorrem como resultado de vários fatores, como: diferenças no material genético, época de maturação, clima/localização geográfica da produção, estação do ano e parte da planta amostrada (GROSS, 1987).

Em geral, em frutos tropicais, o teor de carotenoides totais aumenta durante o amadurecimento, como em laranja (ROTSTEIN et al., 1972) e, carambola (GROSS et al., 1983). Em outros frutos, nos quais a cor do estádio maduro é devido à presença de antocianinas, a exemplo do morango (WOODWARD, 1972) e do "red currant" (GROSS, 1982), o teor de carotenoides diminui com o amadurecimento, ou permanece constante, como em pitanga-roxa (LIMA et al., 2002). Os teores obtidos de carotenoides nos FMSI e FMSS (Tabela 1) estão na faixa de concentração estabelecida por RodriguezAmaya et al. (2008) para a goiaba (Tabela 1); contudo, o aumento na concentração em fruto verde com anelamento, sendo o maior valor presente no FVCI, pode ser atribuído à anomalia causada pelo acúmulo de taninos e fenóis totais, como também observado em pitangas roxa e vermelha por Lima et al. (2002).

Com relação aos flavanoides (antocianinas e flavonas/flavonóis), os tratamentos de FMSS e FMSI apresentaram as menores porcentagens de antocianinas, comparados aos demais tratamentos (Tabela 1), evidenciando sua oxidação em função do amadurecimento do fruto e, consequentemente, queda na concentração dessas substâncias. Isso pode ocorrer, visto que as antocianinas são pigmentos solúveis em água, as quais conferem as várias nuanças de cores encontradas em muitos frutos (FRANCIS, 1989), mas não são majoritariamente as responsáveis por conferir coloração em frutos tropicais (RODRIGUEZ-AMAYA et al., 2008). Entretanto, Tian et al. (2005) e Concellón et al. (2007) concluíram que o aumento na concentração de antocianinas contribuiu significativamente para o aparecimento de manchas marrons em epicarpos de lichia e berinjela, respectivamente. Rezende e Furlan, (2009) relatam que anomalias em folhas de $P$. guajava estão relacionadas às maiores concentrações de antocianinas. Entretanto, no presente estudo, os resultados indicam não haver diferenças significativas na porcentagem de antocianinas, tanto entre os tratamentos (FVCS e FVCI), quanto na comparação deles com os FVSS e FVSI. Portanto, a cor amarronzada não está relacionada com a porcentagem de antocianinas, já que a coloração avermelhada apresentada pela polpa é conferida pela presença de carotenoides e não de antocianina.

A concentração de flavonas/flavonóis nos tratamentos FMSI e FMSS foi significativamente inferior, quando comparada aos demais tratamentos (Tabela 1), devido, provavelmente, ao amadurecimento dos frutos, visto que essas substâncias atuam como co-pigmenos junto às antocianinas (BOBBIO; BOBBIO, 1995; RODRIGUEZ-AMAYA, et al., 2008).

Nos frutos com injúria, há aumento significativo de flavonas/flavonóis em relação aos frutos com mesmo estádio de maturação sem ocorrência de injúria, entretanto sem diferença significativa da concentração entre os tratamentos FVCS e FVCI. 
(a)

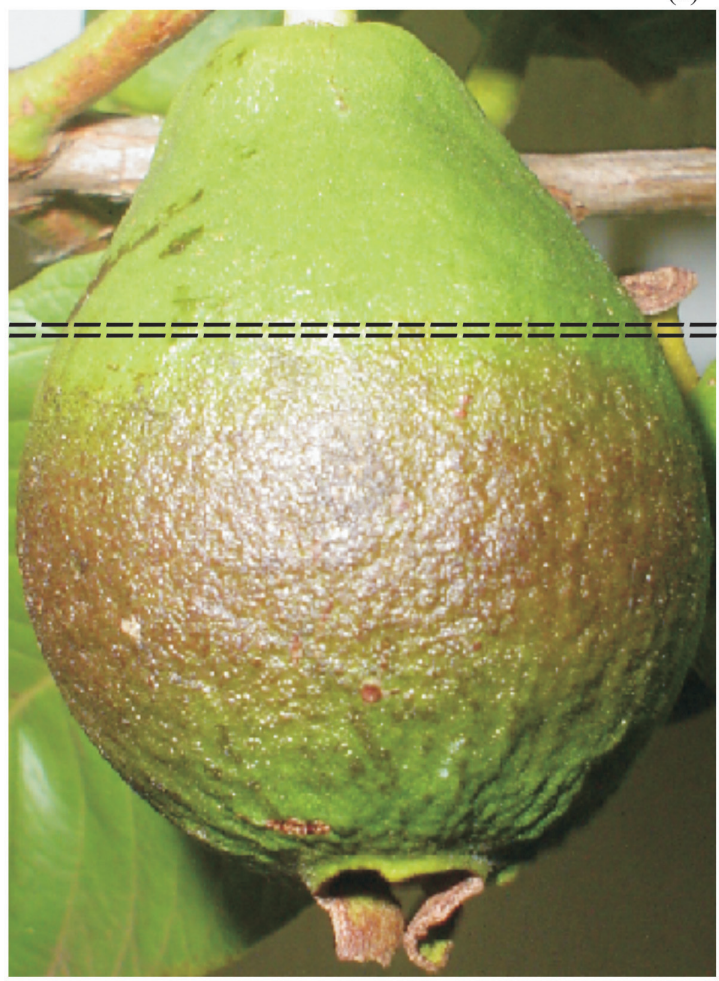

Parte não afetada

(região superior)

Parte afetada

(região inferior)

(b)

(c)
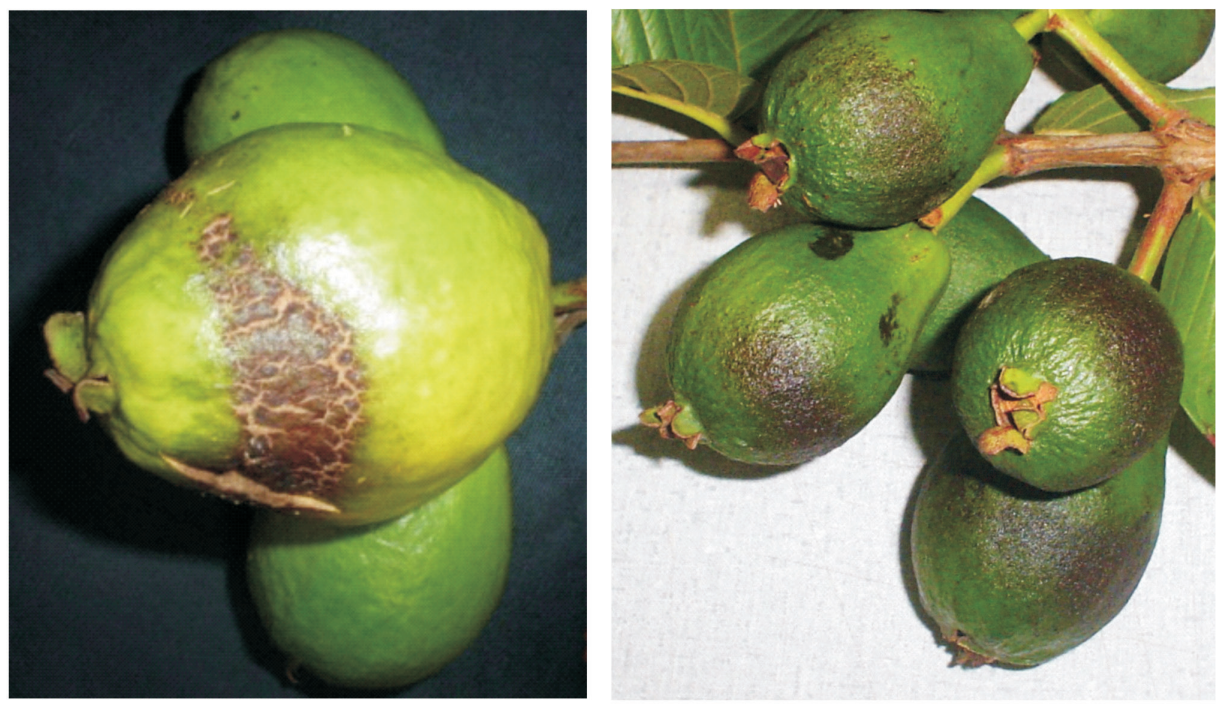

FIGURA 1 - Goiabas 'Paluma' com anomalia característica (“anelamento”) no epicarpo; (a) região delimitada, afetada ou não pela anomalia; (b) fruto com anomalia no epicarpo, isoladamente, em um ramo; (c) ramos com todos os frutos comprometidos pela anomalia. 
TABELA 1 - Comparação das médias dos tratamentos em porcentagem do peso de taninos totais (TT), fenóis totais (FT), antocianinas (AN), flavonas/flavonóis (FF) e Carotenoides (C) em frutos de goiabeira 'Paluma'.

\begin{tabular}{cccccc}
\hline Tratamentos & TT & FT & AN & FF & C \\
\hline & $--16 \mathrm{~d}$ & $0,47 \mathrm{~d}$ & $0,21 \mathrm{~b}$ & $0,04 \mathrm{c}$ & $\% \mu \mathrm{g} \mathrm{g}^{-1}$ \\
FMSI & $0,16,30 \mathrm{~d}$ \\
FMSS & $0,28 \mathrm{~d}$ & $0,60 \mathrm{~d}$ & $0,04 \mathrm{~b}$ & $0,06 \mathrm{c}$ & $2,27 \mathrm{~d}$ \\
FVSI & $1,08 \mathrm{c}$ & $1,16 \mathrm{c}$ & $0,88 \mathrm{a}$ & $0,28 \mathrm{~b}$ & $4,01 \mathrm{c}$ \\
FVSS & $1,21 \mathrm{c}$ & $1,22 \mathrm{c}$ & $0,79 \mathrm{a}$ & $0,27 \mathrm{~b}$ & $5,09 \mathrm{c}$ \\
FVCI & $3,12 \mathrm{a}$ & $2,77 \mathrm{a}$ & $0,95 \mathrm{a}$ & $0,44 \mathrm{a}$ & $11,56 \mathrm{a}$ \\
FVCS & $1,87 \mathrm{~b}$ & $1,70 \mathrm{~b}$ & $0,96 \mathrm{a}$ & $0,40 \mathrm{a}$ & $9,59 \mathrm{~b}$ \\
\hline Teste F & $74,87^{* *}$ & $99,44^{* *}$ & $95,99^{* *}$ & $56,77^{* *}$ & $110,29^{* *}$ \\
\hline CV $(\%)$ & 24,2 & 15,6 & 15,9 & 22,4 & 15,7 \\
\hline
\end{tabular}

** significativo a $\mathrm{p}<0,01$, pelo teste de Tukey.

Frutos maduros sem anomalia na região inferior (FMSI); frutos maduros sem anomalia na região superior (FMSS); frutos verdes sem anomalia na região inferior (FVSI); frutos verdes sem anomalia na região superior (FVSS); frutos verdes com anomalia na região inferior (FVCI); frutos verdes com anomalia na região superior (FVCS)

\section{CONCLUSÕES}

1-Dentre as substâncias analisadas, os carotenoides, os taninos e os fenóis totais mostram indicativos para a caracterização do anelamento.

2-Tanto substâncias fenólicas quanto carotenoides apresentam propriedades antioxidantes e, dessa forma, poderiam estar relacionadas à defesa antioxidante causada por um fator de estresse ainda desconhecido, que promove o "anelamento" característico apresentado pelas goiabas.

\section{REFERÊNCIAS}

AGUILAR,G. A. G.; HERNANDEZ, M. E. T.; GATICA, R. Z.; TELLEZ M. A. M. Methyl jasmonate treatments reduce chilling injury and activate the defense response of guava fruits. Biochemical and Biophysical Research Communications, Yokohama, v. 313, p. 694-701, 2004.

AMERICAN HERBAL PHARMACOPOEIA. Analytical methods and quantitative standards. Disponível em: <http://www.herbal-ahp.org/analytic_guide.htm>. Acesso em: 05 fev. 2010.

BOBBIO, P.A.; BOBBIO, F.O. Introdução à química de alimentos. 2.ed. São Paulo: Varela, 1995. p.223, 1995.
BOLWELL, G. P.; BELL, J. N.; CRAMER, C. L.; SCHUCH, W.; LAMB, C. J.; DIXON, R.A. L-Phenylalanine ammonia-lyase from Phaseolus vulgaris: characterization and differential induction of multiple forms from elicitor-treated cell suspension cultures. European Journal of Biochemistry, West Berlin, v.149, p.411-419, 1985.

CHALKER-SCOTT, L.; KRAHMER, R. L. Microscopic studies of tannin formation and distribution in plant tissues. In: HEMINGWAY, R. W.; KARCHESY, J. J. (Ed.). Chemistry and significance of condensed tannins. New York: Plenum Press, 1989. p.345-368.

COLEY, P. D.; AIDE, T. M. Red coloration of tropical young leaves: A possible antifungal defense? Journal of Tropical Ecology, London, v. 5, p.293300, 1989.

CONCELLÓN A.; AÑÓN, M. C.; CHAVES, A. R. Effect of low temperature storage on physical and physiological characteristics of eggplant fruit (Solanum Melongena L). LWT - Food Science and Technology, Oxford, v. 40, p.411-419. 2007.

ESTAT: sistema para análises estatísticas (v.2.0). Jaboticabal: Polo Computacional, Departamento de Ciências Exatas, FCAV, UNESP, 1992.

FRANCIS, F.J. Food colorants: anthocyanins. Critical Reviews in Food Science and Nutrition, London, v.28, p.273-314, 1989.

GROSS, J. Chlorophyll and carotenoid pigments in Ribes fruits. Scientia Horticulturae, Amsterdam, v.18, p. 131-136, 1982. 
GROSS, J. Pigments in fruits. London: Academic Press, 1987. 303 p.

GROSS, J.; IKAN, R.; ECKHARDT, G. Carotenoids of the fruit of Averrhoa carambola. Phytochemistry, New York, v.22, p.1479-1481, 1983.

IHA, S. M.; MIGLIATO, K. F.; VELLOSA, J.C.R.; SACRAMENTO, L.V. S.; PIETRO, R.C.L.R.; ISAAC, V.L.B.; BRUNETTI, I.L.; CORRÊA,M.A.; SALGADO, H.R.N. Estudo fitoquímico de goiaba (Psidium guajava L.) com potencial antioxidante para o desenvolvimento de formulação fitocosmética. Revista Brasileira de Farmacognosia, João Pessoa, v.18, p. 387-393, 2008.

LIMA, V.L.A.G.de; MÉLO, E. de A.; LIMA, D. E. da S. Fenólicos e carotenoides totais em pitanga. Sciencia Agricola, Piracicaba, v.59, n.3, p.447-450, 2002.

MALDONADO, R.; GARCIA A. D. M.; BALLESTA M. T. S.; ESCRIBANO M. I.; MERODIO, C. High $\mathrm{CO}_{2}$ atmosphere modulating the phenolic response associated with cell adehesion and hardening of Annona cherimola fruit stored at chilling teperature. Food Chemistry, Washington, v.50, p.7564-7569, 2002.

MOTTA, L. B. Análise de metabólitos primários e secundários em galha foliar de Tibouchina pulchra (Cham.) Cogn. (Melastomataceae) e suas relações com tecidos não afetados. 2002. $84 \mathrm{f}$. Dissertação (Mestrado) - Instituto de Biociências, Universidade de São Paulo, São Paulo, 2002.

REZENDE, F. M.; FURLAN, C. M., Anthocyanins and tannins in ozone fomigated guava trees, Chemosphere, Oxford, v. 76, p.1445-1450, 2009.
RODRIGUEZ-AMAYA, D.B.; KIMURA, M.; AMAYA-FARFAN, J. Fontes brasileiras de carotenoides. Brasília: Mistério de Meio Ambiente, 2008. p.100, 2008.

ROTSTEIN, A.; GROSS, J.; LIFSHITZ, A. Changes in the pulp carotenoid pigments of the ripening Shamouti orange. Lebensmittel - Wissenschaft und Technologie, Berlin, v.5, p.140-143, 1972.

ROZANE, D. E.; BRUGNARA, V.; SOUZA, H. A. de; AMORIM, D. A. de. Condução arquitetura e poda da goiabeira para 'mesa' e/ou 'indústria'. In: NATALE, W.; ROZANE, D. E.; SOUZA, H. A. de; AMORIM, D. A. de. Cultura da goiaba do plantio à comercialização. Jaboticabal: FUNEP, 2009. v.2, cap. 17 , p.407-428,

SINGH, J.; AGRAWAL, M.; NARAYAN, D. Relative susceptibility of two species of tropical fruit trees to thermal power plant emission. Journal of Tropical Ecology, London, v. 35, p.83-96, 1994.

TIAN, S. P.; LI, B.Q.; XU, Y. Effects of $\mathrm{O}_{2}$ and $\mathrm{CO}_{2}$ concentrations on physiology and quality of litchi fruit in storage. Food Chemistry, Washington, v.91, p.659-663, 2005.

WATERMAN P. G.; MOLE S. Analysis of phenolic plant metabolites. Oxford: Blackwell scientific publication, 1994. p.92-123.

WELLBURN, A. R. The spectral determination of chlorophylls a and $\mathrm{b}$, as well as total carotenoids, using various, solvents with spectrophotometers of different resolution. Journal of Plant Physiology, New York, v.144, p.307-313, 1994.

WOODWARD, J. R. Physical and chemical changes in developing strawberry fruits. Journal of the Science of Food and Agriculture, London, v.23, p.465-473, 1972. 